\title{
A formaçãa docente do campo: estuda de caso da escola rural Pedro Lovato- RS
}

\section{The teacher education: a case study of a Pedro Lovato rural school in RS}

\section{Resumo:}

O trabalho propõe um exercício de reflexão em formação de professores na perspectiva da educação do campo. Como objetivos, visa analisar a formação docente, especificamente da escola rural Pedro Lovato em Novo Cabrais, RS. O estudo consiste em investigação qualitativa de um fenômeno social, as novas ruralidades, e as especificidades do contexto rural. Conclui-se com o presente estudo, que a partir das especificidade do campo, emerge a necessidade de uma formação de professores específica para a Educação do Campo, associada à produção da vida, conhecimento e produção da cultura do campo.

\section{Abstract:}

The paper proposes a reflection in teacher education from the perspective of rural education. To objectives, this study examining teacher education, specifically the rural school in New Cabrais Peter Lovato, RS. The study consists of qualitative investigation of a social phenomenon, the new ruralities, and the specifics of the rural context. It concludes with the present study that the specificity of the field emerges the need for teacher specific training for Field Education associated with the production of life, knowledge and culture field.
Tatiane Almeida Netto * Cristiane Coradin **

* Engenheira Florestal, Especialista em Geomática, MSc. em extensão rural, doutoranda em Geografía (PPGGEO/UFSM).

Engenheira agrônoma, MSc. em extensão rural.

\section{Palavras-chave:}

ruralidades, sujeitos sociais, educação do campo escola

Key-Words:

ruralities, social subjects, rural education, school 
INTRODUÇÃO

A presente pesquisa se situa, por um lado, Ano campo de discussões e estudos sociológicos, a respeito da construção social de novas ruralidades (CARNEIRO, 2012), adentrando, como temática central, no campo de estudos educacionais, a respeito da formação docente em educação no e do campo (CALDART, 2004).

Sua importância se justifica na medida em que a discussão da emergência das novas ruralidades, recoloca no cenário brasileiro a persistência modificada de um rural resignificado, passando a demandar dos ambientes escolares atualizações estruturais e simbólicas, de modo a manter tais espaços-tempo de aprendizado, bem como de ampliá -los, atualizados e conectados, às demandas desses novos contextos sociais rurais emergentes.

A escola rural deve ser tratada diferentemente da escola urbana, tendo em vista que o contexto, as realidades e as necessidades são diferentes. A legislação brasileira prevê essa diferença e um planejamento vinculado ao meio, através da Lei de Diretrizes e Bases da Educação Nacional (LDB), a qual promove a desvinculação da escola rural e urbana, exigindo um planejamento interligado à vida rural, e uma educação com dimensões sócio-políticas e culturais, com base na cidadania e na prática social (BRASIL/MEC, LDB 9.394/96).

Devemos compreender as especificidades do campo, os vínculos entre território, terra, lugar e escola, os quais contribuem preponderantemente com a formação social, política, cultural e a identidade dos povos do campo (ARROYO, 2007). A aprovação das Diretrizes Operacionais de Educação Básica para as escolas do campo em 2002, possibilitou a legitimação do direto à educação do e no campo, porém sem a devida compreensão desses fenômenos, não seremos capazes de tornar a escola um lugar de formação.

Assim como aponta Menezes Neto (2009) devemos buscar uma educação que não forme alunos apenas como força de trabalho para reprodução do capital, mas sim, uma educação que se vincule à vida camponesa, centrada nos interesses de quem vive do seu trabalho no campo. Neste sentido, compreende-se o campo como espaço de vida, multidimensional, onde se manifestam e realizam as relações sociais, a educação, cultura, produção agrícola, trabalho, infraestrutura, organização política e a construção de mercado, que é produto das relações sociais que se desenvolvem de forma integrada, e não podem ser analisados separadamente.

O objeto de análise da presente pesquisa foi a Escola Estadual Pedro Lovato, localizada no município de Novo Cabrais - RS. A escolha da escola foi motivada pela realização e envolvimento de um dos pesquisadores em projetos sociais de educomunicação ${ }^{1}$ rural, no município de Novo Cabrais, e na região Centro Jacuí, através do Projeto Arquitetos do Saber $^{2}$ (CAPES/Novos Talentos), sob a qual se buscou identificar as características/especificidades da comunidade em que a escola está inserida.

A ênfase da pesquisa incide sobre a compreensão e análise de como a formação docente se constitui e se articula com o processo de inserção das especificidades do contexto rural na escola básica de Novo Cabrais - RS.

Como desdobramentos desse objetivo geral, foram traçados os seguintes objetivos específicos:

a) verificar e compreender se a formação dos professores relaciona-se com as especificidades do campo; e

b) descrever e analisar as propostas de formação docente desenvolvidas pela escola e pela Coordenadoria Regional de Educação.

Nesse sentido, a presente pesquisa visa dar desdobramento acadêmico às ações realizadas no âmbito do projeto de educomunicação, correlacionando dados pré-existentes, com os processos educacionais internos à escola Pedro Lovato, no âmbito da formação docente, enriquecendo o quadro de estudos e práticas de extensão universitária realizados nessa escola rural.

O presente texto está estruturado em quatro partes, das quais a primeira se compõe dessa introdução, a segunda de apresentação do referencial teórico necessário à compreensão do fenômeno em estudo, a terceira da metodologia a ser adotada, apresentando o problema de pesquisa, questões, fontes de informação e procedimentos metodológicos, a quarta contendo as descrições e análises realizadas, e a quinta apresentando as referências utilizadas. 
1. NOVAS RURALIDADES, EDUCAÇÃO DO CAMPO E A FORMAÇÃO DOCENTE

O discurso desenvolvimentista e da modernização da agricultura, em voga no Brasil nos anos 1960-80, atingiram também a educação, na qual o rural passou a ser visto como uma extensão da industrialização, e potencial de liberação de mão de obra para o setor urbano. Para tanto, tornar-se desnecessário o desenvolvimento de processos educacionais no e do campo, centrados em processos educacionais dos habitantes do rural.

Porém, passados anos de modernização, a ruralidade contemporânea insiste em permanecer se resignificando, apontando novas dimensões para a materialização de um novo espaço mercantilizado de bens e serviços, novas possibilidades de negócios, tanto imobiliários quanto voltados ao turismo e lazer, valorizando bens não tangíveis, como paisagem e cultura, recolocando em pauta a discussão do viver e ser no rural, multifuncional (CARNEIRO, 2012).

Para tanto, torna-se necessária à introdução de uma educação do campo voltada ao paradigma da sustentabilidade e à uma nova perspectiva da ruralidade, à preocupação com desenvolvimento humano, social e o ambiental. De tais especificidades atuais do campo, emerge a necessidade de uma Educação do Campo associada à produção da vida, do conhecimento e da cultura do campo, apontando ações para a construção permanente da escola, e para a formação de educadores.

Para o desenvolvimento do campo, é necessária uma política educacional que atenda suas especificidades, que entenda os indivíduos como sujeitos, e não somente como usuários de uso bem público, devendo promover condições adequadas para o desenvolvimento do território, composto pelas particularidades dadas em sua organização familiar e social (FERNANDES, 2005).

Devemos construir a educação como um processo de emancipação, buscando a construção reflexiva e a autonomia dos sujeitos sociais, num processo crítico e participativo, respeitando e utilizando os saberes populares como fontes e resultados da aprendizagem (CALDART, 2004).

Atualmente a educação no campo encontra- se fragmentada em seu processo curricular, desvinculada de um contexto histórico, e distanciada da realidade que o sujeito vive. Ao educando é repassado um pensamento unidimensional, sem destacar e fazer perceber a visão global e integral de sociedade, tornando-se necessária a busca da complexidade ambiental, para uma nova compreensão do mundo, que incorpore o limite do conhecimento e da incompletude do ser, onde se constrói e se aprende, através do processo dialógico de saberes, na hibridação da ciência, das tecnologias e dos saberes populares (LEFF, 2003).

A complexidade ambiental necessita de uma pedagogia do ambiente e de um ambiente da pedagogia, para engajar-se com a vida do campo e, assim, comprometer-se com a equidade e justiça social, e também com valores como a solidariedade, reciprocidade, capazes de selarem um novo contrato solidário entre os sujeitos sociais e a natureza.

Nesse sentido, torna-se fundamental a construção da inter-relação entre o vivido ambiental e social cotidiano, e o vivido no ambiente escolar, a conectividade e integração, em uma dimensionalidade complexa, inter e transdisciplinar entre escola e mundo da vida, articulação capaz de conectar as partes ao todo: a vida cotidiana à vida escolar, tanto nos aspectos ambientais, quanto sociais, econômicos, culturais e políticos (THIESEN, 2008).

Segundo Silva (2004), nos dias atuais, a educação é vista como uma responsabilidade social dos governantes perante a população, a escola básica é o espaço para aquisição de habilidades, competências e conhecimentos fundamentais ao exercício da cidadania, possibilitando a construção da dignidade humana.

É então, pela centralidade que a escola assume no desenvolvimento sustentável no campo, que se aponta para a necessidade da realização de estudos, experiências e proposições políticas eficazes, capazes de fortalecer ambientes escolares rurais, em estreita conexão com as demandas e contextos das realidades sociais sob os quais possam ser situar.

A educação do campo tem como princípio, processos de construção de conhecimentos, que procuram contribuir com o desenvolvimento dos territórios do campo, entendidos como espaços de 
vida, sociabilidades, de produção de cultura, política, de relação com o meio ambiente e de produção econômica.

Para o desenvolvimento do campo é necessária uma política educacional que atenda suas especificidades, que compreenda os sujeitos como atores e não somente como usuários. A educação pode vir a promover as condições políticas essenciais para o desenvolvimento do território, composto pelas particularidades, na sua organização por meio do trabalho familiar (FERNANDES, 2005).

A educação do campo está fortemente ligada ao conceito de educação popular desenvolvida por Paulo Freire. O conceito segundo Paulo Freire parte da realidade das práticas sociais, leva em conta o local, a região em que vive o educando e tem como objetivo primordial a inserção deste no processo educativo, de modo vivo e dinâmico, incluído numa política de desenvolvimento.

Tornar popular a educação indica para a sua universalização e democratização em diferentes níveis, tornando-a de fato acessível às camadas populares. Acessíveis pela via do conhecimento e da cidadania, frente às condições necessárias à transformação social e à emancipação humana, finalidade da ação político-pedagógico. É uma estratégia de construção da participação popular para o redirecionamento da vida social.

A Educação Popular é uma educação comprometida e participativa, orientada pela perspectiva de realização de todos os direitos do povo, o processo de ensino-aprendizagem, que é visto como ato de conhecimento e de transformação social, sendo pautado na perspectiva política. Sua principal característica é utilizar o saber da comunidade como matéria prima para o ensino, aprender a partir do conhecimento do sujeito, e ensinar a partir de palavras e temas geradores do cotidiano dele.

Educar é saber "ler" o mundo, conhecê-lo para transformá-lo e, ao transformá-lo, conhecê-lo (GADOTTI, 2003). Para desenvolver a educação, é necessário metodologias participativas, da hermenêutica, da pedagogia da complexidade, voltadas para a problematização dos diferentes sentidos, interesses e forças sociais, que se organizam em torno das questões ambientais e sociais.

A população do campo tem o direito de pen- sar o mundo a partir do lugar em que vive, a partir da sua realidade, pois no momento em que o sujeito do campo pensa o mundo a partir da realidade da cidade, do meio urbano, leva ao estranhamento de si mesmo, o que dificulta a construção da identidade, condição fundamental da formação cultural e da cidadania (FERNANDES, 2002).

Nesse processo educativo, a formação docente, condizente com as múltiplas funcionalidades e transformações atuais do mundo rural, ancorada na relação entre as especificidades locais e a sociedade global, cumpre papel fundamental, sem a qual dificilmente as sociedades conseguirão avançar na construção social de uma educação do campo, factualmente ativa, propositiva, complexa, reflexiva, problematizadora e transformadora da realidade social.

Para Tonet (2007) e Silva [19--] aos educadores compete a construção de consciência crítica, voltada para a emancipação dos sujeitos. Ela deve possibilitar o conhecimento da história da humanidade, seus dilemas, contradições, conflitos, compreender a função social da educação. Cuja natureza essencial significa a apropriação de conhecimentos, valores, comportamentos, que constituem o acumulado histórico da humanidade, de modo a atualizá-los, contribuindo na formação de sujeitos históricos, que fazem, participam da história ativamente, e ao participar ativamente, tornam-se capazes de transformá-la.

A formação docente deverá ser contextualizada e promotora de condições adequadas para que os educadores consigam correlacionar e problematizar as realidades do mundo rural, atentando para as especificidades de cada território, ao mesmo tempo em que vinculem tais reflexões ao conjunto dos conteúdos disciplinares, processos e procedimentos metodológicos específicos desenvolvidos em cada área de atuação e da educação de modo global, com vistas à construção social da formação dos sujeitos e de consciência crítica.

São processos que abrangem diversos campos de conhecimentos, ancorados na necessidade de compreensão da formação social, histórica, econômica, política, cultural e ambiental das populações do campo e do globo, transpondo gerações, como memória, atualização e criação de novos 
conhecimentos. Para Martins ([20--] p. 305) “[...] os sujeitos envolvidos nesse processo devem se perceber enquanto sujeitos históricos e políticos com capacidade para construir e modificar os rumos da história".

Além disso, deve ser compreendida como um processo complexo, baseado em uma perspectiva teórica e prática da complexidade, capaz de ultrapassar as fragmentações dos campos de conhecimentos disciplinares de cada área de ensino dos professores. Isso significa que, segundo Silva ([19--], p. 103) "o trabalho do professor é educar pessoas e conhecer a complexidade dos processos de aprendizagem, do desenvolvimento do ser humano em suas diferentes gerações e culturas".

Entendida como processo complexo e dialético, ela deve ser contínua e continuada, deve contemplar atividades tais: como o diagnóstico da realidade em suas diversas dimensões sociais, culturais, econômicas, políticas, ambientais; a problematização de tal contexto; a construção de propostas; a experienciação; a análise, avaliação e reelaboração e construção de nova prática. Também devendo favorecer o amadurecimento e aperfeiçoamento profissional dos docentes.

De acordo com o Documento "Referências para uma Política Nacional de Educação do Campo", caderno de subsidio que tem balizado as reivindicações para ações público estatais quanto à educação do campo fica claro que:

[...] Uma Política Pública de Educação do Campo deve respeitar todas as formas e modalidades de educação que se orientem pela existência do campo como um espaço de vida e de relações vividas, porque considera o campo como um espaço que é ao mesmo tempo produto e produtor de cultura (BRASIL, 2003, p.31).

Nesse sentido, a formação docente, proposta enquanto componente fundamental da política pública de educação do campo, a ser implementada por instâncias e agências público estatais, deve orientar-se pela construção ativa e crítica da realidade social dos discentes, docentes e gestores escolares.

Como princípios, a formação docente oferecida pelos órgãos públicos estatais, necessita ser compreendida e assimilada por esses sujeitos, como um direito dos povos do campo, respeitando as organi- zações sociais, e os conhecimentos por elas produzido; realizada no campo; entendida como produção de cultura; voltada para a formação de sujeitos e para o desenvolvimento sustentável, respeitando as características do campo (BRASIL, 2003).

Para tanto, necessita-se de que as estruturas sociais, principalmente público estatais, responsáveis pela realização de tal processo formativo, ofereçam boas condições de trabalho aos professores, tais como possibilidades de convívio e compreensão do campo, conteúdos e conhecimentos articulados e significativos, condizentes com as orientações teórico-metodológicas da educação do campo, e com os seus campos específicos de conhecimento, remuneração e infraestrutura adequadas, jornadas de trabalho não exaustivas, planos de carreira, de modo que o ser e o fazer docente seja um ato agradável, produtivo e amistoso, tanto para docentes, quanto para os discentes e gestores escolares (BRASIL 2003).

A partir da construção social de visões de mundo complexas, dialéticas, interativas e dinâmicas, contemplando a compreensão das múltiplas dimensões do campo, envolvendo-as à estrutura e dinâmicas educacionais, espera que se possa avançar na construção social de processos educacionais que aproximem as sociedades da emancipação dos sujeitos sociais.

\section{CAMINHOS E PASSOS DA PESQUISA}

A presente pesquisa tem enfoque no empirismo, e se caracteriza como investigação de um fenômeno social contemporâneo, dentro de seu contexto real. É substancialmente uma pesquisa de caráter exploratório e descritivo, à qual aprecia a utilização de diferentes métodos e abordagem qualitativa para análise dos dados, buscando aprofundar a análise, e não apenas conhecer os fatos de forma sumária, possibilitando reflexão sobre o tema.

Para desenvolver essa pesquisa, foi utilizada a educação do campo como referencial teórico, entendida como análise crítica da questão agrária, e da busca de autonomia dos territórios e sujeitos sociais, e meio de construção social de perspectivas transformadores das realidades sociais.

A análise consiste na reflexão do processo da 
formação docente, a partir da experiência dos sujeitos envolvidos, considerando a temática do rural e a educação do campo, presente nos processos educativos.

O cenário da pesquisa é a Escola A E.E.E.F. Pedro Lovato, fundada em 1953, localizada no centro da localidade de Cortado no município de Novo Cabrais, próxima a Igreja Católica (Paróquia São Claudio), sendo a única Escola de Ensino Fundamental da localidade. Atualmente a escola consta de 12 professores, 3 funcionários e 85 alunos.

A comunidade escolar, pertencente à localidade de Cortado, é composta de oitenta famílias, oriundas do meio rural, cuja principal atividade econômica é a agricultura familiar, tendo como destaque o cultivo do fumo e soja. Cortado está localizado ao sudoeste do município de Novo Cabrais, fazendo divisa com os municípios de Paraíso do Sul e Cerro Branco.

A localidade do Cortado é uma das primeiras regiões povoadas de Novo Cabrais. Possui uma população de aproximadamente 1.000 habitantes, em sua maioria de origem italiana. $\mathrm{O}$ acesso à localidade se dá através da RSC 287, tendo a localidade uma extensão de aproximadamente $9 \mathrm{Km}$, com um relevo privilegiado e uma cultura específica, em relação com a sociedade.

As principais características das propriedades da localidade, como área, posse e permanência no local, evidenciam a característica da agricultura familiar da localidade, onde 50\% compreendem até 15 ha de área total, $45 \%$ são proprietários das terras e residem em média no local há 41 anos (Estudo da realidade rural- localidade Cortado-Novo Cabrais/ RS, 2011).

Importante se faz o estabelecimento de um enfoque metodológico que se relacione à necessidade de obter uma aproximação com sujeitos (no caso professores da escola rural Pedro Lovato), que desvelem a essência de suas vivências e experiências, que possibilite a captura das perspectivas dos participantes, buscando entendê-los numa totalidade concreta.

Visando atentar para tais questões, optou-se pela realização de entrevistas semiestruturadas divididas em: a) grupo focal de professores da Escola Pedro Lovato; e b) entrevista semiestruturada indi- vidual a Coordenadoria Regional de Educação da Região de Cachoeira do Sul- RS, especificamente a equipe responsável pela educação do Campo.

Essas opções metodológicas possibilitaram aos autores realizar aproximação entre entrevista e observação, valendo-os do papel de mediadores dos diálogos estabelecidos entre os entrevistados. Martins ([20--]) afirma que quando utiliza os sentidos, na obtenção de determinados aspectos da realidade, não consiste apenas em ver e ouvir, mas também em examinar fatos ou fenômenos que se deseja estudar. Gondim (2002) destaca que os sujeitos participantes da pesquisa encontram no Grupo Focal liberdade de expressão, que é favorecida pelo ambiente, levando a uma participação efetiva.

No dizer de Gatti (2005) ao se fazer uso da técnica do Grupo Focal, "há interesse não somente no que as pessoas pensam e expressam, mas também em como elas pensam e por que pensam". Disso procede a importância de utilizar essa técnica na pesquisa. Sendo os sujeitos artífices da história, sofrendo influência do meio social, mister se faz desvelar este como e porquê pensam, na busca de novas compreensões, de novo olhar no caleidoscópio da ciência, que apresenta para nós sempre novas possibilidades e até mesmo com surpresas (BARBOUR, 2009).

\section{FORMAÇÃO DOCENTE DO CAMPO: OLHARES E PERSPECTIVAS}

Para análise da temática, os autores se referenciaram em uma racionalidade ambiental, inter, transdisciplinar e emancipatória (THIESEN, 2008; MORIN, 1999; LEFF, 2003; FREIRE, 1988, 1997), capaz de lhes auxiliar no entendimento das conexões vivenciadas, possíveis e desejáveis de serem vivenciadas nos ambientes escolares, traduzindo-se em ações e metas concretas e materializáveis, capazes de contribuir com a construção de novos paradigmas educacionais e societários, entendendo a educação enquanto processo, movimento integrado e reflexivo. Para tanto, as análise foram divididas em olhares docentes e da coordenadoria de educação.

Na pesquisa de campo, o grupo focal realizado com os professores, contemplou a presença de cinco, dos doze professores que trabalham na escola. A maioria deles atuam tanto na Escola Pedro 
Lovato, quanto em outras escolas na região. Dos cinco professores, quatro residem na área urbana da cidade de Cachoeira do Sul, e um na cidade de Novo Cabrais. Todos afirmam conhecer superficialmente o contexto rural da localidade de Cortado e do Município, através de pesquisas realizadas na localidade anteriormente, promovidas pelo Projeto Arquitetos do Saber.

Os professores da escola realizam formações regionais, voltadas ao ensino básico, através da Coordenadoria Regional de Educação. Essas formações são realizadas por áreas do conhecimento, nas quais discutirem os processos de ensino-aprendizagem de suas áreas do conhecimento e fundamentos globais da educação. Não necessariamente realizam essa formação conjuntamente com os professores da escola Pedro Lovato, e por vezes realizam em município próximo, muitas vezes vinculados à um contexto urbano, com base em aportes metodológicos.

Os professores analisam que nessas formações que recebem, há pouco tempo para diálogo e troca de experiências, pois os palestrantes falam muito, abrindo pouco tempo para diálogo e problematização. Além disso, afirmam que por vezes essas formações são invasivas da autonomia docente: "como você vai receber uma bagagem de uma semana para te dizer: vai trabalhar assim, assim ...."

$\mathrm{Na}$ escola, cada professor se apropria dos conhecimentos e conteúdos específicos de sua área do conhecimento e disciplina, tentando desenvolver com os discentes algumas atividades vinculadas às especificidades do contexto rural local. Segundo eles, a formação que recebem é genérica, e compete a eles adaptarem seus planos de ensino e práticas pedagógicas às demandas do contexto local e regional.

Alguns professores relataram que os conteúdos vão sendo direcionados de acordo com a realidade dos discentes, pois acreditam que o planejamento de ensino precisa se relacionar com o meio onde eles vivem, enfatizando a necessidade de voltar o olhar para a realidade dos alunos. Há preocupações em não "engessar" os planos de ensino, em mantê-los flexíveis, mas ao mesmo tempo, há também a preocupação em "vencer os conteúdos" das disciplinas.
O contexto estrutural descrito acima, aponta para desconexão institucional do meio rural dos ambientes escolares, manifesta na não construção de espaços coletivos de reflexão, problematização e construção de planos de ensino, estratégias de aprendizagem e projetos correlacionados entre as disciplinas, e contextualizadas com o perfil do campo do município, movimento que não agregam na construção de uma visão complexa e dialética do ambiente escolar, a medida em que não favorecem a ocorrência de situações que estimulem o desenvolvimento teórico-prático de tal abordagem (LEFF, 2003; CALDART, 2004)

Outrossim, tal ação interdisciplinar a voltadas ao meio rural, embora não encontre lócus formal, na estrutura organizacional da escola, por vezes acontece, mesmo sem ser planejada. Notou-se que ela emerge, em meio às reflexibilidades e adaptações que os professores constroem em suas práticas docentes.

Observou-se através dos relatos, por exemplo, que no ensino de línguas foi desenvolvido um projeto sobre a Butterfly, no qual os discentes trouxeram lagartas do fumo, do maracujá para a sala de aula, onde foi discutido em inglês o ciclo da borboleta. Esse processo possibilitou a construção significativa do conhecimento dos discentes, os quais, segundo a professora, se conscientizaram de que "se a gente mata a lagarta com veneno, não nasce à borboleta". Além disso, por se tratar de um tema transversal, foi emergindo a possibilidade de articulação dessa disciplina com outras disciplinas das turmas, ligadas ao ensino de português e ciências naturais. $O$ que possibilitou discussões no âmbito das ciências naturais de temas como ecologia e saúde, problematizando-se os limites e problemas decorrentes do uso de herbicidas, pesticidas no campo e para a saúde humana.

Aqui é necessário descrever que a agricultura familiar de Novo Cabrais é baseada economicamente na produção e venda de fumo, atividade altamente tóxica, construída a partir de elevados índices de agrotóxicos, passíveis de geração de inúmeros problemas para a qualidade do meio ambiente, fauna, flora e microbiologia dos ecossistemas e também para a saúde humana.

Nesse sentido, a problematização ecológica e 
sanitária do tal tema se torna altamente relevante nos espaços escolares, na medida em que incitam reflexões e problematizações a respeito de suas práticas sociais, de suas famílias, do ambiente e relações sociais que estabelecem no território, evidenciando contradições do agronegócio, manifestado em sua relação de degradação do meio ambiente e da saúde humana, favorecendo, dessa forma, a construção social de sujeitos ativos, reflexivos e problematizadores de suas realidades sociais (CALDART, 2004).

No olhar dos professores das ciências, eles percebem que há interfaces com a geografia, e que ações desenvolvidas nessas disciplinas podem por vezes ser correlacionadas, porém, dizem não planejar ações conjuntas, quando ocorrem, elas emergem, acontecem.

Em outras áreas, como línguas, educação física, matemática, física, avaliam que seja mais difícil contextualizar os conteúdos das aulas com o mundo rural, acreditam que as áreas mais próximas à natureza possam oferecer melhores condições. No entanto, contraditoriamente, nos apresentaram a experiência da Butterfly, que partiu do ensino de inglês, envolvendo a disciplina de português e de ciências.

No ensino da Geografia, a professora analisa que "os livros de geografia não tem nada a ver com a realidade do aluno", que para todas as cidades são ofertados os mesmos livros. Segundo ela, os livros não têm nada sobre a paisagem do rural a partir da realidade do aluno, as adaptações eles que precisam construir, para tornar o aprendizado dos conteúdos significativos para os discentes.

Já no ensino da educação física, o professor afirma que não há diferenças, que tanto rural quanto urbano são iguais, nesse sentido, não promove adaptações em suas aulas, além de que avalia que para si, as formações pedagógicas que recebe pouco contribuem.

Os professores, segundo seus depoimentos, sentem dificuldades em realizar essas adaptações, avaliam que precisariam ter melhores condições de trabalho (tempo, assistência educacional qualificada), pois trabalham em outras escolas e também precisam ter vida social, não podem se intensificar os ritmos de trabalho, além de que, não conseguem construir espaços coletivos para reflexão das pro- blemáticas de ensino-aprendizagem da escola.

Por meio desses relatos, depreende-se que a interdisciplinaridade acontece em alguns casos específicos, que ela não é elaborada, refletida. Apesar de ser desejada, não alcança a estrutura organizacional da escola, lócus de inserção contínua, o que pode dificultar a construção de processos educacionais complexos, baseados em uma complexidade ambiental (LEFF, 2003; THIESEN, 2008).

Além disso, a interdisciplinaridade é vista como potencialmente realizável, somente em algumas disciplinas, contradizendo as suas práticas, as quais, segundo os relatos, ofereceram condições de construir conhecimentos significativos, partindo do ensino de inglês, envolvendo o ensino de português e ciências.

Outra questão relevante observada, foi o distanciamento dos instrumentos didáticos dessa perspectiva teórico-prática, tais como livros didáticos, os quais, segundo uma das professoras, não oferece contornos significativos com o contexto geográfico da região e localidade, o que torna mais difícil construir o conhecimento junto com os discentes, de modo que se associe a sentidos e significados práticos para esses.

Tanto as práticas quanto os conteúdos e materiais didáticos, devem, de acordo com Gadotti (2003) partir da realidade social dos discentes, de sua realidade empírica, para que os processos de ensino-aprendizagem tornem-se significativos, e o desvendar da realidade, seja o desvendar de si, como atividade, como meio de mudança, transformação de si e do meio social, pilares fundamentais à condição da construção social de sujeitos.

Um dos professores relatou aos pesquisadores que escolheu trabalhar no rural, por analisar que os perfis dos alunos são diferentes. Percebe que eles têm acesso à internet, informação, mas que seu processo de acolhimento das iniciativas pedagógicas e processos de abstração são diferenciados dos alunos da cidade. Conta que realizou jogos ecológicos com os alunos e teve boa aceitabilidade. Segundo ele: "aqui tem a família, outros gostos, é outro perfil de alunos".

Ele relata que sabe dos alunos que querem estudar e ir embora, e aqueles que não querem. Segundo ele, alguns alunos dizem: "para que eu vou 
estudar, se vou seguir plantando fumo?" Se deparando com tais situações, o professor diz problematizar tais argumentações, enfatizando a necessidade de "estudarem para não serem passados para trás", ainda que continuem plantando fumo.

O que se percebe é que elementos significativos do mundo rural do Distrito de Cortado, aparecem em sala de aula, e são abordados de modo reflexivo pelos professores. Porém, percebe-se que, como tais representações giram em torno da produção do fumo e do esvaziamento do campo, os professores, pela ausência de formação adequada, capaz de lhes prover condições de abordar a temática de modo ampliado e aprofundado, articulado às suas disciplinas e de forma integrada, não conseguem articular essa problematização, para além da questão ambiental e sanitária, com outros temas, tais como a construção de alternativas viáveis para o convívio de melhoria das condições de vida no campo.

Eles não chegam a refletir a relação entre agricultura familiar e dependência com o agronegócio, a redução da produção de alimentos para consumo e a especialização produtiva focada no fumo. Tampouco as atividades desenvolvidas na escola, como cuidados com o jardim pomar, plantas, espaços verdes potencialmente utilizáveis para tais fins, tem sido pedagógicas, no sentido de conseguir-se avançar na construção de outras representações sobre o rural, resignificando-o, ou seja, o rural, sob o olhar dos professores, ainda permanece sendo algo visto como atrasado (CARNEIRO, 2012).

Perde-se, com isso possibilidade de qualificação dos processos reflexivos do campo com os estudantes, limita-se, dessa forma, a construção de perspectivas educacionais voltadas à educação do campo, de acordo com os princípios elencados por Caldart (2004).

Quanto à formação docente na escola, os professores afirmam que às vezes aparecem na escola instituições e pessoas querendo ensinar eles a darem aula e que eles não gostam disso. Analisam que as pessoas que vem fazer a formação, precisam estar contextualizadas e capacitadas para realizar tais formações.

Os professores destacam que nos últimos anos algumas palestras de formação de profes- sores, articuladas pela direção da escola, têm sido realizadas pelos integrantes do Projeto Arquitetos do Saber, em parceria com a UFSM. Nesse projeto, são desenvolvidas ações que tentam articular as especificidades do mundo rural, com processos educativos globais, buscando-se revitalizar os espaços verdes da escola, construir-se pomares, hortas, composteiras, etc. Os professores avaliam que essas formações que têm sido relevantes, porém, analisam que deveriam ser oferecidos mais espaços e serem mais focados.

Percebe-se que há disposição de alguns professores para a construção conjunta de tais atividades, avaliam como sendo pertinentes, que podem contribuir com melhorias com a escola. Porém, se apreende que, o limitado envolvimento dos docentes com a escola, morando distantes, associado ao baixo envolvimento da comunidade local com a escola, são fatores que dificultam a construção coletiva de estratégias de positivação do ambiente escolar, voltado à uma complexidade ambiental e pedagogia reflexiva da realidade social (LEFF, 2003; CALDART, 2004).

Outro problema enfrentado no âmbito da formação e prática docente na escola, são as resistências internas às mudanças. Um deles nos relatou que por vezes chegam à escola pessoas com novas ideias, com vontade de promover mudanças e não conseguem implementar, pois encontram barreiras internas, construídas a partir de compreensões e visões de mundo da educação e do dia-a-dia escolar já cristalizadas, sem perspectiva de mudanças. Quando tais pessoas 'novas' se deparam com esses contextos, tendem a se frustrar, e a se acomodar com as práticas já instituídas, comportamentos e valores dos professores mais velhos.

Isso demonstra a presença de potenciais conflitos geracionais e de visões de mundo no ambiente escolar. Onde alguns possuem receptividade à mudanças, busca de novos conhecimentos, aperfeiçoamento e construção de adaptações, favorecendo a construção de perspectivas de educação adaptadas ao contexto rural e às dinâmicas dos alunos, e outros menos ou mesmo que nem se quer apresentam tal disposição. São distintas visões de mundo, comportamentos, valores sociais, morais, que em relação entre si, acaso associem-se a inflexibilidades 
relacionais, tendem a atuar como elementos reforçadores da fragmentação disciplinar e de educação não reflexiva.

Em síntese, considera-se que há esforço de parte dos professores em gerar ações educacionais que visem articular o contexto e o meio com suas disciplinas e entre as disciplinas, e também demanda permanente pela qualificação de sua atuação, através de processos formativos adaptados, qualificados e suficientes para aperfeiçoamento de suas ações nas escolas. No entanto, desestímulos internos, bem como falta de melhores condições de trabalho tem constrangido a melhor atuação dos mesmo nos ambientes escolares.

\section{A FORMAÇÃO DOCENTE SOB O OLHAR DA COORDENADSORIA REGIONAL DE EDUCAÇÃO}

A formação docente no âmbito da Coordenadoria da Regional de Educação, com sede na cidade de Cachoeira do Sul, é dividida entre ensino médio, educação do campo e ensino profissional.

Para a formação específica em educação do campo até 2011, havia o Programa de Formação de Professores Escola Ativa, que realizava formação mensal com os professores, abordando a temática do universo rural. Em 2012 esse Programa não aconteceu, segundo a coordenadoria, o Programa Escola da Terra substituiria o Escola Ativa, mas ele não foi implantado, nesse sentido, desde o ano de 2012, não vem acontecendo formações específicas mensais em educação do campo para os professores que lecionam em escolas rurais.

Nas formações direcionadas exclusivamente as escolas do rural (quando aconteciam mensais), o foco das reuniões foram os estudos socioantropológicos, movimentos sociais, interdisciplinaridade e gestão escolar.

Atualmente está em voga a discussão sobre a implementação dos ciclos trienais nas escolas rurais do RS. Para fazer o processo de adaptação dos professores, estão previstas formações mensais, contando com as 24 escolas rurais da regional, a partir de 2014. Tais formações deverão contemplar a temática do mundo rural, retomando com os professores os processos formativos que aconteciam no Escola Ativa.

Quanto à formação realizada pelo Estado do
RS (instancias responsáveis pela educação em nível estadual), acontece em uma semana antes das férias, nesse período também ocorre durante 12 dias, formações com a Coordenadoria Regional de Educação, mesclando professores do campo e da cidade, não sendo, portanto, formação específica para o mundo rural e educação do campo.

Nas formações voltadas para o campo são realizadas palestras e oficinas, cujos palestrantes são escolhidos por temas e conhecidos dos articuladores da Coordenadoria de Educação Regional. Também são chamados técnicos da área da agricultura, e não somente profissionais da educação.

A coordenadoria busca construir parcerias com entidades que trabalham com agricultura, como EMATER, porém, observa que existe resistência no campo em construir-se tais parcerias, analisam que há dificuldades em as instituições assumirem compromisso com esses processos formativos. Nessas formações, os professores são convocados a participar.

Para a Coordenadoria está em curso um processo de perda da identidade do rural. Sob esse olhar, percebe-se que nas escolas do rural há falta de identificação da escola com o contexto rural. São universos distintos, que não se encontram, não encontrando espaços para diálogo e construções coletivas entre os docentes de possibilidades de atuação diferenciada.

A representante da coordenadoria cita em contraponto, o exemplo da Escola de Estrela, onde os processos de ensino-aprendizagem adquirem sentido para os alunos, contando com o envolvimento dos pais, os quais vão à escola para explicar, fazer junto com os discentes, como fazer receitas, atividades agrícolas, ensinando os saberes e fazeres do campo. E isso, ela relata faltar na escola em estudo.

Segundo a Coordenadoria, esse deveria ser o empenho dos professores das escolas rurais da regional, atuando, na construção de outros olhares sobre o rural, na sua positivação enquanto território de vida, dignidade e sociabilidade, para além do esvaziamento e especialização produtiva, servindo-se também como lócus de transmissão e recriação de conhecimentos, práticas e saberes do campo.

Para a Coordenadoria, nas atividades formati- 
vas em educação do campo, os momentos de trocas de experiência acontecem e são espaços ricos. Ao relatar sobre a experiência da escola de Estrela, afirma que "antes uma coisa era ouvir falar, agora eles viram". Tal experiência representa para a Coordenadoria, a possibilidade de impulsionar os professores a promoverem mudanças em seus planos de ensino e práticas pedagógicas, assumindo olhares inter e transdisciplinares, dialéticos, contribuindo com a construção de sujeitos sociais, produtores de história e de vida social no campo.

Percebeu-se que no âmbito da Coordenadoria Regional de Educação há compreensão teórica e prática dos referencias da educação do campo, bem como intencionalidade de abordar de modo permanente no processo de formação dos docentes essa temática. Porém, analisa-se que embora o discurso da coordenadoria esteja baseado nos princípios norteadores da construção da educação do campo, o mesmo não consegue refletir-se na prática da formação docente, tendo em vista os conflitos geracionais e constrangimentos institucionais, que tem limitado a construção efetiva, na prática de abordagens transdisciplinares e contextualizadas do mundo rural na formação docente.

\section{A FORMAÇÃO DOCENTE EM REFLEXÃO}

A partir dos elementos até aqui apresentados, analisa-se que, de modo geral, a formação dos professores, tanto aquela que acontece na escola, quanto a promovida pela Coordenadoria, da maneira como está formalmente organizada na atualidade, não considera os contextos formativos e escolares dos professores e dos alunos, tendo em vista suas histórias, saberes e experiências pessoal-profissionais.

Além disso, também observa-se que os professores raramente têm tido oportunidade, espaço e tempo para falar, debater, teorizar sobre seu trabalho sobre sua própria formação. A prática educacional em grande medida é preenchida por ações prescritas nos calendários escolares e execução das aulas, com baixo envolvimento escolar dos professores, sem ter-se em perspectiva a construção de sistemáticas formativas, no interior da escola e comunidade local, em articulação com a formação promovida pela coordenadoria, de abordagem interdisciplinar, baseada na construção de uma educação do campo, tal como entendida por Caldart (2004).

Os tempos de formação, bem como os conteúdos oferecidos e mesmo as formações que tem chegado às escolas por meio de parceiros tem sido insuficientes para poder-se qualificar os professores para abordarem a educação com oação reflexiva e contextualizada ao meio rural.

Outrossim, esses professores, mesmo sem adquirir aporte de tempo e conteúdo específico, seja dentro da escola, ou no âmbito da coordenadoria, tem realizado esforços, no sentido da construção de ações individuais e algumas entre seus pares, visando articular o contexto rural de Cortado a alguns conteúdos abordados em sala de aula, promovendo, espontaneamente ações interdisciplinares.

Outro fato interessante identificado, e que impacta a formação docente, tal como percebido por um dos professores da Escola Pedro Lovato, foram os conflitos inter-geracionais vivenciados nas escolas. Notouse maior abertura e facilidade de diálogo e disposição à inovação diante de professores jovens, em relação àqueles que fase de se aposentarem ou já aposentados, os quais demonstram menos disposição de geração de mudanças educacionais, e mesmo em suas posturas pedagógicas, no sentido da construção de uma abordagem da educação do campo.

Esse fator geracional, associado aos constrangimentos e limites institucionais, aparecem como elementos principais de entraves ao avanço na construção de um outro perfil de educação no campo, voltada ao mundo rural, à autonomia, construção e emancipação de sujeitos. Pois se não há recursos humanos, capital e aporte institucional local, regional e estadual, bem como disponibilidade e compreensão dos docentes quanto a necessidade de mudanças, inovações, adaptações, contemplando as demandas do rural, dificilmente pode-se conseguir avançar na construção de atualizações possíveis e necessárias no campo da educação, e especialmente da educação do campo (GADOTTI, 2003).

\section{CONSIDERAÇÕES FINAIS}

Da realização dessa pesquisa de campo, se pode apreender que atualmente acontece ausência de uma educação voltada para as especificida- 
des sociais e culturais dos que vivem ali, tendo em vista que não tem acontecido processos formativos formais específicos em educação do campo para os professores da Escola Estadual Pedro Lovato.

As formações institucionais tem sido genéricas, promovidas pela coordenadoria de educação, e tem sido insuficientes para suprir as demandas de qualificação continuada dos professores. Mesmo assim, com as possibilidades cabíveis a cada qual, alguns professores tem se esforçado em realizar ações interdisciplinares e que visem contemplar os contextos locais durante as aulas.

O conjunto dos limitantes tanto internos quanto externos à escola, tem constrangido a construção social de novas perspectivas educacionais, contextualizadas ao seu meio e promotoras da construção social de sujeitos sociais.

Por fim, visualiza-se, como perspectiva, que para os próximos anos, possa-se novamente resgatar processos formativo em educação do campo, ampliando e qualificando os processos formativos dos docentes, a partir da transição das turmas multisseriadas para ciclos educacionais de três anos. Tal imposição da atual política educacional deve por si só coagir aos professores que se busque um maior comprometimento a escola do campo e a sua formação para atuação nela.

\section{REFERÊNCIAS BIBLIOGRÁFICAS}

ARROYO, M.G. Políticas de formação de educadores(as) do campo. Cad. Cedes, Campinas, v. 27, n. 72, p. 157-176, maio/ago. 2007.

BARBOUR, R. Grupos focais. Porto Alegre: Artmed, 2009.

BRASIL. Lei no 9.394, de 20 de dezembro de 1996. Lei de Diretrizes e Bases da Educação Nacional, Brasília, DF, 1996. Disponível em: < http://portal. mec.gov.br/arquivos/pdf/ldb.pdf > Acesso em 21 jul. 2013.

BRASIL. Referências para uma Política Nacional de Educação do Campo. Caderno de subsídios. Brasília, outubro, 2003.
CALDART, R. Por uma educação do campo: traços de uma identidade em construção. In: ARROYO, M.G.; CALDART, R.; MOLINA, M. Por uma educação do campo. Petrópolis: Vozes, 2004.

CARNEIRO, M. J. (coor.) Ruralidades contemporâneas: modos de viver e pensar o rural na sociedade brasileira. Rio de Janeiro: Mauad X/FAPERJ. 2012.

FERNANDES, B.M. Os campos da pesquisa em educação do campo: espaço e território como categorias essenciais. I ENCONTRO NACIONAL DE PESQUISA EM EDUCAÇÃO DO CAMPO. Anais... Brasília, set. 2005.

FERNANDES, M. F. Diretrizes de uma caminhada. In: Edgar, J. K.; Paulo, R. C.; Roseli, S C. (Orgs). Educação do campo: Identidade e políticas públicas. Brasília, DF: Articulação nacional por uma educação do campo, 2002, p. 89-103.

FREIRE, P. Pedagogia do oprimido. $18^{\mathrm{a}}$ ed. Rio de Janeiro: Paz e Terra, 1988.

FREIRE, P. Pedagogia da autonomia: saberes necessários à prática educativa. 3. ed. Rio de Janeiro: Paz e Terra, 1997.

GADOTTI, M. Saber aprender: um olhar sobre Paulo Freire e as perspectivas atuais da educação. In: LINHARES, C.; TRINDADE, M. N. (Orgs.). Compartilhando o mundo com Paulo Freire. São Paulo: Cortez, 2003.

GATTI, B. A. Grupo focal na pesquisa em ciências sociais e humanas.Brasília: Líber Livro, 2005.

GONDIM, S.M.G. Grupos focais como técnica de investigação qualitativa: desafios metodológicos. Paidéia (Ribeirão Preto), v. 12, n. 24, 2002. Disponível em: $<$ http://www.scielo.br/scielo.php?script=sci arttext\&pid>. Acessado em: 04 de jul. de 2013.

LEFF, H. La complejidad ambiental. Mexico: Siglo XXI, $2^{\mathrm{a} e d .} 2003$.

MARTINS, M. F. A. Educação do campo: formação de professor por área, desafios da área de Ciências Sociais e Humanidades. [20--]. Disponível em: < http:// educanp.weebly.com/uploads/1/3/9/9/13997768/ 
educao_do_campo-_formao_de_professor_por_ rea_desafios_da_rea_de_cincias.pdf> Acesso em: 06 de jul. de 2013.

MENEZES NETO, A. J. de. Formação de Professores para a educação do campo: projetos sociais em disputa. In: ROCHA, M.I.A.; MARTINS, A. A. (Orgs.). Educação do Campo: desafios para a formação de professores. Belo Horizonte: Autêntica, 2009.

SILVA, I.M.S. Formação de professores no e do campo e a UNESCO: uma nova estratégia? [19--]. Disponível em: < http://www.utp.br/cadernos_de_pesquisa/ pdfs/cad_pesq11/6_formacao_professores_cp11. pdf $>$. Acesso em 04 de jul. de 2013.

SILVA, M. do S. Educação do Campo e Desenvolvimento: uma relação construída ao longo da história. 2004. Disponível em: http://www.contag.org.br/imagens/ f299Educacao_do_Campo e Desenvolvimento_Sustentavel.pdf > Acesso em: 02 de jul.de 2013.

SOARES, I. de O. Caminos de la educomunicación: utopías, confrontaciones, reconocimientos. Nómadas, Universidad Central, Bogotá, (30), p. 194-207, 2009.

THIESEN, J. S. A interdisciplinaridade como um movimento articulador no processo ensino-aprendizagem. Revista Brasileira de Educação, v. 13, n.39 set./ dez. 2008. p.545-598.

TONET, I. Educação contra o capital. Alagoas: EDUFAL, 2007.

\section{Notas de Fim:}

1- Soares (2009) conceitua educomunicação um campo de reflexão /ação, que partilha da critica da racionalidade instrumental adota a prática social e a ação comunicativa, para ponderar o processo social em um espaço de ações e experiências. A educomunicação surge para socializar e criar consensos, a partir das alianças dos agentes sociais envolvidos e atuantes no processo, desenvolvendo a criticidade, autogestão e a capacidade de expressão do grupo social e sujeitos em questão.

2- O projeto Arquitetos do Saber foi importante na construção do objeto desta pesquisa, pois proporcionou maior contato com o público rural, através do desenvolvimento de oficinas nas escolas rurais.

\section{Correspondência das autoras:}

Tatiane Almeida Netto e-mail: tatinetto@yahoo.com.br

Cristiane Coradini

e-mail: cristianecoradin@yahoo.com.br

Artigo recebido em: 10/11/2014

Revisado pelas autoras em: 04/09/2015

Aceito para publicação em: 15/10/2015 